University of Nebraska - Lincoln

DigitalCommons@University of Nebraska - Lincoln

Public Health Resources

Public Health Resources

2020

Evaluating Gene Drive Approaches for Public Benefit

Michael R. Santos

Follow this and additional works at: https://digitalcommons.unl.edu/publichealthresources

Part of the Genetics and Genomics Commons, and the Medicine and Health Sciences Commons

This Article is brought to you for free and open access by the Public Health Resources at

DigitalCommons@University of Nebraska - Lincoln. It has been accepted for inclusion in Public Health Resources

by an authorized administrator of DigitalCommons@University of Nebraska - Lincoln. 


\title{
Evaluating Gene Drive Approaches for Public Benefit
}

\author{
Michael R. Santos
}

\begin{abstract}
Gene drive approaches - those which bias inheritance of a genetic element in a population of sexually reproducing organisms - have the potential to provide important public benefits. The spread of selected genetic elements in wild populations of organisms may help address certain challenges, such as transmission of vector-borne human and animal diseases and biodiversity loss due to invasive animals. Adapting various naturally occurring gene drive mechanisms to these aims is a long-standing research area, and recent advances in genetics have made engineering gene drive systems significantly more technically feasible. Gene drive approaches would act through changes in natural environments, thus robust methods to evaluate potential research and use are important.

Despite the fact that gene drive approaches build on existing paradigms, such as genetic modification of organisms and conventional biological control, there are material challenges to their evaluation. One challenge is the inherent complexity of ecosystems, which makes precise prediction of changes to the environment difficult. For gene drive approaches that are expected to spread spatially and/or persist temporally, responding to this difficulty with the typical stepwise increases in the scale of studies may not be straightforward after studies begin in the natural environment. A related challenge is that study or use of a gene drive approach may have implications for communities beyond the location of introduction, depending on the spatial spread and persistence of the approach and the population biology of the target organism. This poses a particular governance challenge when spread across national borders is plausible. Finally, community engagement is an important element of responsible research and governance, but effective community engagement for gene drive approaches requires addressing complexity and uncertainty and supporting representative participation in decision making.

These challenges are not confronted in a void. Existing frameworks, processes, and institutions provide a basis for effective evaluation of gene drive approaches for public benefit. Although engineered gene drive approaches are relatively new, the necessities of making decisions despite uncertainty and governing actions with potential implications for shared environments are well established. There are methodologies to identify potential harms and assess risks when there is limited
\end{abstract}

M. R. Santos $(\square)$

Foundation for the National Institutes of Health, North Bethesda, MD, USA

e-mail: msantos@fnih.org 
experience to draw upon, and these methodologies have been applied in similar contexts. There are also laws, policies, treaties, agreements, and institutions in place across many jurisdictions that support national and international decision making regarding genetically modified organisms and the potential applications of gene drive approaches, such as public health and biodiversity conservation. Community engagement is an established component of many decision-making processes, and related experience and conceptual frameworks can inform engagement by researchers.

The existence of frameworks, processes, and institutions provides an important foundation for evaluating gene drive approaches, but it is not sufficient by itself. They must be rigorously applied, which requires resources for risk assessment, research, and community engagement and diligent implementation by governance institutions. The continued evolution of the frameworks, processes, and institutions is important to adapt to the growing understanding of gene drive approaches. With appropriate resources and diligence, it will be possible to responsibly evaluate and make decisions on gene drive approaches for public benefit.

Keywords Gene drive · Risk assessment - Governance - Community engagement · Biosafety $\cdot$ Public benefit $\cdot$ Decision making $\cdot$ Uncertainty

\section{Gene Drive Approaches: Potential to Provide Important Public Benefits}

Gene drive is a phenomenon of biased inheritance in which the prevalence of a genetic element is increased, even in the presence of some fitness cost, leading to the preferential increase of a specific genotype that may determine a specific phenotype from one generation to the next and potentially throughout a population (National Academies of Sciences, Engineering, and Medicine (NASEM) 2016). Gene drive is a natural phenomenon observed in populations of many different organisms; there are multiple natural mechanisms that lead to gene drive, and the phenomenon has been described with various names (Burt and Trivers 2006). An important property of gene drive is that the genetic element that increases in frequency in the population can decrease individual fitness compared to a context without the driving genetic element. Normally a genetic element conveying a fitness cost would be selected against over time, because offspring that do not inherit the element will outcompete those that do. However, under some circumstances, the drive effect can outweigh a fitness cost (e.g., Burt 2003). This property of gene drive has long been recognized as potentially enabling applications that spread traits in wild populations of organisms, even if the trait does not convey a fitness advantage (e.g., Craig et al. 1960; Von Borstel and Buzzati-Traverso 1962; Curtis 1968).

The features of gene drive enable potential applications of gene drive approaches for public benefit (e.g., Esvelt et al. 2014; NASEM 2016; Australian Academy of 
Science 2017). The contexts where gene drive approaches may be most applicable are those where the organism of interest reproduces sexually with a short generation time (compared to timescales of interest) and there is well-mixed mating across the relevant populations (e.g., Burt 2003; Esvelt et al. 2014). There is long-standing interest in gene drive approaches to reducing transmission of vector-borne human and animal diseases (e.g., Serebrovsky 1940; Craig et al. 1960; Curtis 1968; Ribeiro and Kidwell 1994; Burt 2003, 2014). Given the success of vector control in reducing the burden of vector-borne diseases (e.g., vector control interventions accounted for $78 \%$ of the reduction in malaria prevalence from 2000 to 2015; Bhatt et al. 2015), complementary gene drive approaches may be transformational tools to eliminate or eradicate vector-borne disease (NASEM 2016; NEPAD and the African Union 2018). There is also current interest in biodiversity preservation (e.g., through population reduction of invasive species or increased resilience for endangered species; Redford et al. 2019), agricultural pest control (e.g., Scott et al. 2018), and crop resilience (e.g., Pixley et al. 2019). Gene drive approaches can be particularly well suited to public benefit because their benefits would accrue to everyone in the area of use.

Gene drive approaches may provide a useful complement to other approaches to important public goals and should be considered in that context. The potential applications of gene drive approaches are pursued through a variety of means currently, such as insecticides/pesticides/rodenticides, conventional removal of invasive species, conventional biocontrol, breeding programs, and genetic modification (e.g., NASEM 2016). In many cases existing interventions are insufficient or undesirable (e.g., Feachem et al. 2019, for the case of malaria eradication, where cost and widespread insecticide resistance limit the impact of current tools, and Campbell et al. 2015 , for the case of invasive rodents, where cost and toxicity limit the impact of toxicants). Gene drive approaches may complement existing interventions by being lower cost (because of potential spread and persistence) and species specific in their direct effect. As discussed above, gene drive approaches may also promote equity because their benefits accrue to the areas in which they are used, rather than to individuals, and thus do not depend on individual resources such as wealth and time; inequity may still exist between areas that have access to gene drive approaches and those that do not.

Given the potential for gene drive approaches to provide public benefit, there has been research into adapting or recapitulating a variety of natural gene drive mechanisms in organisms of interest, such as disease vectors. This research resulted in important advances, such as the first implementation of gene drive in a malaria vector (Windbichler et al. 2011), and has accelerated dramatically since 2015 due to the application of improved genome editing tools, such as CRISPR-Cas-based tools, to engineering gene drive (e.g., Dicarlo et al. 2015; Gantz and Bier 2015). There have been notable successes in laboratory cage experiments with malaria vectors, demonstrating proof of principle of genes that reduce the population of vectors (Hammond et al. 2016) and reduce mosquitoes' ability to transmit the parasites that cause malaria (Gantz et al. 2015). Although resistance to the gene drive mechanism may be expected over time (e.g., Burt 2003), different drive mechanisms may be 
more or less susceptible to the development of resistance, and techniques have been identified to delay its development (e.g., Burt 2003; Esvelt et al. 2014; Hammond et al. 2017; Kyrou et al. 2018; Champer et al. 2018); in addition, gene drive approaches will often not need to operate indefinitely to deliver their public benefit. Despite these many technical advances, gene drive is still a difficult phenomenon to engineer: highly efficient gene drive has been reported in only a handful of organisms and has been difficult to implement even in well-studied animals like mice (e.g., Grunwald et al. 2019; see also Godwin et al. 2019 and Yosef et al. 2019). To date, research into genetically engineering gene drive approaches has occurred exclusively in laboratory containment, and no genetically engineered gene drives have been introduced into the natural environment.

The advances in genome editing tools are generally expected to enable demonstrations of more varieties of gene drive. Among the principal areas of research are efforts to engineer control over the spatial spread and temporal persistence of the driving genetic element. Possible approaches include systems where the drive mechanism functions only when present above a threshold (e.g., Akbari et al. 2013; Oberhofer et al. 2019), which tends to limit the spatial spread of the genetic element, and generational limits on the persistence of the gene drive mechanism (e.g., Noble et al. 2019), after which natural selection will remove genes with fitness costs from the population. Another potential method for limiting spread is using a drive mechanism that operates on a specific genetic sequence that is prevalent only in a restricted subpopulation (e.g., Sudweeks et al. 2019). In addition to engineering a priori control into gene drive approaches, there is active research on methods to stop the spread of a driving genetic element (e.g., Esvelt et al. 2014; Vella et al. 2017; Basgall et al. 2018; Roggenkamp et al. 2018).

Given the potential for gene drive approaches to contribute to important social priorities like human and animal health and biodiversity, and the technical progress in engineering them, the potential challenges associated with gene drive approaches for public benefit have become a topic of serious consideration for stakeholders (e.g., NEPAD and the African Union 2018; Redford et al. 2019). Gene drive approaches have similar challenges to other activities that make changes to the natural environment, such as establishing a nature reserve or building a hydroelectric dam: ecosystems are complex and the consequences of interventions are difficult to predict with precision, the environment is spatially interlinked (naturally and through humanassisted transportation) so some local interventions can have effects beyond the location of intervention, and within the affected areas it is not possible for individuals to personally opt in or opt out of the effects (e.g., National Research Council 2005).

The following sections discuss the challenges of evaluating gene drive approaches for public benefit and methods for addressing them. There is an increasing diversity of potential applications and technical strategies for gene drive approaches with a wide spectrum of possible properties; thus it is not possible to evaluate them as one group (NASEM 2016). The subsequent sections highlight concepts and methods that may have applicability in case-by-case evaluation of specific gene drive approaches. 


\section{Challenges of Evaluating Gene Drive Approaches for Public Benefit}

\section{Decision-Making Context}

The decision-making contexts within which gene drive approaches are evaluated are important to understanding the challenges. Because the public benefit use cases generally concern impact on communities and the shared environment, there are structures already in place for making decisions related to those goals, such as ministries of health responsible for infectious disease control and ministries of environment responsible for endangered species preservation and biodiversity. In addition, gene drive approaches, depending on their specifics, may be subject to biosafety regulations, policies, and laws, implemented by national biosafety authorities. For gene drive approaches where the responsibilities of multiple regulatory and policy interests intersect, effective integration can be difficult (e.g., NASEM 2017).

The governance of decisions on gene drive approaches - the decision-making and accountability mechanisms - includes laws and treaties as well as "soft law" tools such as guidelines, recommendations, and norms (NASEM 2016). Researchers and their institutions play a governance role through their own ethical considerations (often represented for institutions by institutional review boards or independent ethics committees) and peer- and funder-imposed norms (e.g., Akbari et al. 2015; Emerson et al. 2017). The responsibility to decide on the use of gene drive approaches is principally within governments, typically at the national level but potentially also at sub-national levels, and among governments through international treaties and agreements such as the Cartagena Protocol on Biosafety to the Convention on Biological Diversity [CBD] (Secretariat of the CBD 2000). Governance processes at all levels are generally organized for case-by-case evaluations.

There is a continuum of decisions required for potential research and use of gene drive approaches (NASEM 2016). For research, the common process is that researchers propose activities that, where necessary, are externally evaluated. Laboratory studies of gene drive approaches within containment are typically subject to biosafety review (e.g., UC San Diego Institutional Biosafety Program 2018). Governance becomes stricter as the likelihood and magnitude of potential undesirable outcomes of a decision ("harms") are judged to increase; for example, the Cartagena Protocol on Biosafety includes requirements that apply to the introduction of living modified organisms into the environment that do not apply to contained use (Secretariat of the CBD 2000; see, e.g., Maiga 2018 for the authorization of a field study of a living modified organism without a gene drive approach). Decisions regarding use, meaning introduction with direct public benefit as the primary goal, encompass potentially separate decisions about what uses are permitted (regulatory authorization decisions), what uses are actually implemented (policy and financing decisions), and what the responsibilities are for harms that are a consequence of use (liability decisions). For example, biosafety regulators and ministries of environment may be responsible for determining under which circumstances, 
if any, gene drive approaches to reducing malaria transmission are allowed; ministries of health and national malaria control programs may be responsible for deciding if and where gene drive approaches will be funded and delivered; and national laws and international treaties may establish liability associated with potential harm due to use of the approach (James et al. 2018).

The essential considerations for decision making on gene drive approaches for public benefit are evaluations of potential benefits, costs, and harms and their likelihoods (NASEM 2016); these considerations are elements of processes like costbenefit analyses. Benefits, costs, and harms are subjective evaluations that depend on values, which differ among individuals and organizations (National Research Council 2005). As highlighted above, there may be multiple organizations with responsibility for authorization of a specific gene drive approach; these organizations will have different statutory responsibilities that influence the scope, scale, and weights of potential benefits, costs, and harms they consider in their evaluations (e.g., NASEM 2017). These evaluations will typically share a common objective: to establish potential outcomes associated with proposed research or use of gene drive approaches and consider the likelihoods of those outcomes.

\section{Uncertainty of Potential Benefits, Costs, and Harms}

A significant challenge for the evaluation of gene drive approaches is uncertainty in the likelihoods of potential benefits, costs, and harms: ecosystems are generally complex and there is limited experience with gene drive approaches (NASEM 2016). The challenge of uncertainty is not specific to gene drive approaches or biotechnology: large uncertainties are common in the evaluation of many environmental changes, such as fisheries management (e.g., Schwaab 2014), road construction (e.g., Zhao et al. 2004), use of conventional biocontrol organisms (e.g., Benjamin and Wesseler 2016), conservation to protect endangered species (e.g., Nicholson and Possingham 2007), conventional removal of invasive species (e.g., Kessler 2011), and reintroduction of extirpated native species (e.g., Carroll et al. 2019). In contexts of high uncertainty, particularly regarding potential harms, phased testing paradigms use stepwise increases in the scale of studies to balance reduction of uncertainty, exposure to potential harms, and speed of evaluation. For example, the scale of studies for a gene drive approach might progress successively from physical containment to semi-field studies under outdoor confinement, small-scale open field studies, and, finally, larger-scale introductions (NASEM 2016). Each step provides a higher-fidelity representation of real-world use, thus further reducing uncertainty about the expected outcomes of use, but also increases the potential exposure to harms. Thus after each step the accumulated evidence informs the decision on whether to proceed to the next step; the intensity of governance also typically increases through the stepwise process.

There may be limitations to the application of the phased testing paradigm to some gene drive approaches. The paradigm is applicable for the earlier phases of 
research, within physical confinement. However, some gene drive approaches would be expected to spatially spread and temporally persist after the first introduction to the natural environment, even if that introduction were in the context of a field trial. Even when gene drive approaches include mechanisms to control spread and/or persistence, the efficacies of those control mechanisms won't be known until they are tested in the field. For these reasons, field trials of some gene drive approaches may be evaluated similarly to decisions about small-scale introductions, where a greater degree of environmental exposure is assumed (e.g., James et al. 2018).

The ability to detect incipient harms and respond to, eliminate, or reduce them is an important component of the evaluation of potential harms of gene drive approaches; this ability is likely to vary substantially across specific cases of gene drive approaches (NASEM 2016). In general, the complexity of ecosystems may make it difficult to determine whether any changes in the environment that happen after the introduction of a gene drive approach were caused by the gene drive approach. The potential for some gene drive approaches to spread and persist from relatively low prevalence in a population may present an obstacle to circumscribing the location where risk response is necessary, even when an effective conventional response (e.g., conventional vector control or invasive species removal) is available. Gene drive approaches designed to stop the effects of a previously introduced gene drive may have particular advantages for removing an undesired gene drive approach from the environment (e.g., Vella et al. 2017), but with the associated uncertainty of introducing another gene drive approach.

\section{Potential Spread and Persistence}

The potential spatial spread and temporal persistence of some gene drive approaches create another important challenge. Depending on the scale of introduction, population biology of the target species, and specifics of the approach, communities beyond the location of introduction of a gene drive approach may be affected (e.g., Marshall 2009). Which communities will be affected, and when, will depend on properties of the gene drive approach and natural environment (e.g., North et al. 2019).

As a consequence, decision makers such as regulators could be asked to evaluate gene drive approaches expected to spread outside of their jurisdictions, including across national borders (e.g., Brown 2017). Policymakers will need to consider the legal and political implications of the potential spread of gene drive approaches; in particular, the spread of genetically modified organisms across international borders is regulated under the Cartagena Protocol on Biosafety (for countries that are signatories; Secretariat of the CBD 2000). Legal risks associated with liability and redress will be particularly consequential for decisions about potential implementation of approved gene drive approaches (e.g., Oye et al. 2014; Glover et al. 2018). 


\section{Community Engagement}

Consultation with stakeholders, in particular with communities where research or use of gene drive approaches is being considered, is an important element of the evaluation of gene drive approaches (e.g., NASEM 2016). For researchers, engagement with affected communities is an ethical obligation (e.g., King et al. 2014). This responsibility includes providing transparency into the research being conducted, so that concerns can be identified and addressed, and obtaining community acceptance of the research (e.g., World Health Organization 2014). In addition, community engagement by researchers creates an opportunity for co-development of innovation, where community input is expected to improve the quality of the research (e.g., NEPAD and the African Union 2018; Hartley et al. 2019). For other decision makers, such as regulators, policymakers, and implementers, community engagement is commonly an element of their decision-making process (e.g., Quinlan et al. 2016). For example, many environmental regulators include opportunity for public comment on their pending decisions, local policymakers often convene meetings of their constituents to address questions and concerns, and international governance institutions like the Convention on Biological Diversity commonly invite online comments on topics under consideration.

There are likely to be multiple elements to the challenge of successful community engagement in decision making (e.g., Kaebnick et al. 2014; Quinlan et al. 2016; NASEM 2016). Because of the potential uncertainties in spatial spread and temporal persistence of gene drive approaches, it may not be known exactly what areas and communities will be affected and when (e.g., Baltzegar et al. 2018). Communicating effectively given the scientific complexity and uncertainty of gene drive approaches may also be difficult (e.g., Brossard et al. 2019). Gene drive approaches will have area-wide effects that, like existing community interventions, do not allow for opting in or opting out at the level of the individual (e.g., Thizy et al. 2019); elements of research, such as social science research or access to private property, may still require individual consent (e.g., Kolopack and Lavery 2017). Governments routinely make decisions for communities, though the degree and mechanism for representation and participation vary; for research, community acceptance is less well defined than individual consent, and achieving representative perspectives from communities can be difficult (e.g., Kaebnick et al. 2014; Thizy et al. 2019). Given that the elements of the challenge of community engagement will vary with each individual consideration of a gene drive approach, similar to risk assessment there is unlikely to be a single prescriptive process appropriate for all gene drive approaches (e.g., Rask and Worthington 2015; NASEM 2016). 


\section{Conclusion}

Effective evaluation of gene drive approaches for public benefit depends on these challenges being successfully addressed. The next section discusses the groundwork that is already in place and additional efforts required to accomplish this.

\section{Addressing the Challenges of Evaluating Gene Drive Approaches for Public Benefit}

The previous section highlighted three important challenges for evaluating gene drive approaches for public benefit. The first is that the expected environmental, social, and economic effects of the introduction of a gene drive approach will have uncertainties, a consequence of the inherent complexity of ecosystems and societies and limited experience with gene drive approaches. The second is that research or use of a gene drive approach may affect areas beyond the location of introduction, including potentially in other countries. The third is that community engagement by researchers and other decision makers is important but not straightforward. These challenges are common to other decisions about the shared environment, and thus there are existing frameworks, processes, and institutions that can help address them.

\section{Managing Uncertainty in Decision Making}

Uncertainty is a common challenge in decision making, and there are frameworks to help characterize and reduce uncertainty (e.g., Aven et al. 2014). Risk assessment, a set of methods to identify and analyze potential outcomes of decisions (e.g., Rausand 2011), is one of those frameworks and is recognized as important to the evaluation of gene drive approaches (e.g., NASEM 2016; Secretariat of the CBD 2000). Risk assessment is a general and flexible framework that can identify potential harms and characterize their likelihood. Risk assessment methods can address potential health, social, cultural, economic, and environmental harms. The potential harms considered in any individual risk assessment will depend on the organization performing it. For example, when regulators perform risk assessments, the scope of potential harms considered is typically prescribed by laws and policies. Some decisions about gene drive approaches, such as policies about their use, are likely to be informed by risk assessments considering different categories of potential harms. 
The first step in risk assessment is identification of potential harms within the scope that is being considered. Identifying harms can incorporate analogous prior experience (e.g., through checklists of previously experienced harms), and new potential harms can be enumerated through systematic processes: situations that could conceivably lead to harms are identified (e.g., for gene drive approaches for African malaria vectors, Roberts et al. 2017; Teem et al. 2019), and the chain of events from the decision to potential harms is articulated. The next step in risk assessment is the evaluation of the likelihoods of each potential harm (including different types and magnitudes of consequences for a given type of harm); this evaluation can be qualitative or quantitative (e.g., Rausand 2011). When there is a lack of relevant experience to inform the likelihoods (such as for potential harms that have never occurred), the likelihood of a potential harm can be inferred from the likelihoods of the events on the causal pathway to that harm: often there are data to inform the likelihoods of individual events even when the full pathway is unprecedented (e.g., Hayes et al. 2018a). For example, in fault tree analysis the events on the causal pathway to a harm are identified along with their logical relationships; when the probabilities of the individual events are estimated, they can be combined into an estimate of the probability of harm. The estimated likelihoods of harm have uncertainties, which can additionally be characterized, including quantitatively (e.g., Kaplan and Garrick 1981). Risk assessment conducted in this manner can also inform further research on gene drive approaches: by characterizing the expected likelihoods of harms and the uncertainties associated with those expectations, research studies and monitoring plans can be developed to prioritize reduction of the most consequential uncertainties.

Structured risk assessment methods have been applied across a range of complex systems, including to living modified organisms (e.g., Hayes et al. 2018a). Risk assessment is a component of many regulatory frameworks, and in particular ecological risk assessment is used by many environmental authorities (e.g., US EPA 2019; EFSA n.d.) and specifically recommended for the evaluation of gene drive approaches (NASEM 2016). The Cartagena Protocol on Biosafety requires "case-bycase," "scientifically sound" risk assessment for international transboundary movement of living modified organisms intended for use in the environment (Secretariat of the CBD 2000). No genetically engineered gene drive approach has advanced to the stage of risk assessment, but independent probabilistic risk assessments have been released for the contained use and small-scale field release of a genetically sterile malaria vector in Burkina Faso (Hayes et al. 2015, 2018b), demonstrating methods that could be applied to risk assessments of gene drive approaches.

\section{Governing Gene Drive Approaches That Could Cross Borders}

Similar to gene drive approaches, many environmental decisions have implications beyond the area in which they are implemented, and there are frameworks and institutions to support those decisions. Of particular relevance are decisions in a country 
that can affect other countries, such as use of water from a shared source (e.g., General Assembly of the United Nations 1997). International governance institutions such as regional organizations (e.g., the European Union, the African Union) and the United Nations provide platforms for international treaties and agreements, which can inform national laws and policies. Specifically, international institutions exist to support decision making on living modified organisms (e.g., the Cartagena Protocol on Biosafety) and potential applications of gene drive approaches such as public health (e.g., the World Health Organization) and biodiversity conservation (e.g., the Convention on Biological Diversity). These institutions provide binding requirements and guidance to participating countries that apply to gene drive approaches, including provisions for liability and redress in cases where a living modified organism used within a country moves to another country and causes harm (e.g., the Nagoya-Kuala Lumpur Supplementary Protocol; Secretariat of the CBD 2011). Regional institutions can also provide guidance on the development of regional regulatory frameworks and capacity (e.g., in the African Union, Glover et al. 2018, and specifically for gene drive approaches for malaria, African Biosafety Network of Expertise 2018).

\section{Effectively Engaging Communities in Decisions}

Although community engagement is expected to be challenging for research and use of gene drive approaches, there are examples to learn from and frameworks to guide future efforts. For example, foundational features of the community engagement approach of the Eliminate Dengue/World Mosquito Program have been functionally related to their impact, which may be informative for other approaches (Kolopack et al. 2015). There are relevant engagement frameworks that have been developed for genetically modified mosquitoes (e.g., Lavery et al. 2010; World Health Organization 2014; Thizy et al. 2019; Singh 2019), mice that carry tick-borne pathogens (Buchthal et al. 2019), and biodiversity (e.g., Rask and Worthington 2015). The Cartagena Protocol on Biosafety requires its signatories to promote public awareness, understanding, and participation in the decision-making process for living modified organisms (which many possible gene drive approaches would be categorized within), and there is an ongoing program of work within the Protocol to advance priority areas (UN Environment Programme 2016).

In summary, these frameworks highlight the importance of "an expansive notion of "engagement" (Bartumeus et al. 2019). Identifying communities, stakeholders, and publics for engagement, accounting for the uncertainties associated with spread and persistence, needs to be continuous because those identifications are likely to evolve (NASEM 2016). Engagement early and throughout the research process provides transparency and enables co-creation of approaches (e.g., Esvelt 2017; Hartley et al. 2019). Communication should use language appropriate to different audiences so that messages are understandable (e.g., 
Quinlan et al. 2016). Finally, a common refrain is the importance of financial resources and human capacity dedicated to community engagement, for research (e.g., King et al. 2014) and in government decisions (UN Environment Programme 2016).

\section{Conclusion}

Collectively, the existing appropriate frameworks, processes, and institutions provide a context to address the challenges of evaluating gene drive approaches for public benefit. Established methods can characterize the expectations and uncertainties for research and use of a gene drive approach, such as the range of areas and communities that may be affected. Institutions exist to use that information to make decisions given their responsibilities and processes, and national and international governance enables decision making across communities beyond those in which a gene drive approach is introduced. Community engagement will need to be tailored for each individual case, but past experience and conceptual frameworks can guide these important activities. The next section closes with important considerations for the effective application of this context to evaluate gene drive approaches for public benefit.

\section{Recommendations on Decision Making for Gene Drive Approaches}

Having identified the context that can help address the challenges to evaluating gene drive approaches, the effective application of that context requires resources to implement risk assessment, support research, and engage communities; diligent implementation by governance institutions; and the continued evolution of the frameworks, processes, and institutions.

Rigorous evaluation of gene drive approaches may be resource intensive, similar to other regulatory decisions, and appropriate regulatory capacity is required. Some governance institutions may already possess sufficient capacity, and in other cases capacity strengthening may be a necessary precursor to evaluation of gene drive approaches. International organizations can and should play an important role in supporting capacity development (e.g., Glover et al. 2018).

Research is an important tool to inform the potential benefits, costs, harms, and likelihoods of different outcomes from the use of a gene drive approach. Baseline environmental studies can help characterize population biology and ecosystem relationships (e.g., Moro et al. 2018) and contained use studies may reduce other uncertainties (e.g., Hayes et al. 2018a). Mathematical modeling can provide insights into 
potential outcomes of research or use of gene drive approaches over a range of potential contexts (e.g., Sánchez et al. 2019). Ethical, legal, and social science research will continue to inform fair and effective approaches for making decisions (e.g., National Research Council 2005; NASEM 2016). It is important that these research areas receive sufficient funding to provide informative input into the evaluation of gene drive approaches.

Decisions about gene drive approaches for public benefit, like other important public decisions, should be made with diligence, rigor, and transparency, with the understanding that a just process will produce decisions that are unlikely to satisfy every stakeholder. It is a role of governments to fairly represent the values of their constituencies in decision making, recognizing that even in processes widely recognized as good governance, such as free and fair elections, a large minority of constituents may disagree with the decision (e.g., UN General Assembly 1966). In addition, some gene drive approaches may have the potential to spread across national boundaries, requiring national authorities to act on their international obligations.

The frameworks, processes, and institutions that exist to address the challenges of evaluating gene drive approaches should continuously improve the support they provide for decision making. Given the limited current experience with gene drive approaches, it will be valuable to continue to refine the methods for identifying and characterizing potential outcomes. Governance at the national level evolves, and regular convenings of international institutions provide venues to further interpret treaties and agreements and develop guidance. Community engagement methods will continue to be informed by experience from research and governance of gene drive approaches and analogous domains. Progress in these areas, including on international liability and redress, is a necessary complement to technical progress on gene drive approaches (e.g., Oye et al. 2014). For example, the Ad Hoc Technical Expert Group on Risk Assessment of the Cartagena Protocol on Biosafety is specifically tasked with informing decisions on whether additional guidance for risk assessment of genetically engineered gene drive approaches is necessary (UN Environment Programme 2018).

Gene drive approaches have the potential to provide important public benefits by making changes in the natural environment. Evaluating them will be challenging for decision makers: ecosystems are complex, governing changes that can affect multiple communities is complicated, and there is limited experience with the use of gene drive approaches. However, these challenges are not confronted in a void. Because making decisions about the shared environment under conditions of uncertainty is a common responsibility across many domains, there are existing frameworks, processes, and institutions that can help address these challenges. If the appropriate resources and diligence are applied, it will be possible to responsibly evaluate and make decisions on gene drive approaches for public benefit.

Acknowledgments I gratefully acknowledge thoughtful input on this contribution from four anonymous reviewers, colleagues at the Foundation for the National Institutes of Health, Western Michigan University, EHS Consultancy, and the Commonwealth Scientific and Industrial Research Organisation. 


\section{References}

African Biosafety Network of Expertise (2018) Establishment of the West Africa integrated vector management programme. http://nepad-abne.net/establishment-of-the-west-africa-integratedvector-management-programme-accra-19-august-2018/

Akbari OS, Matzen KD, Marshall JM et al (2013) A synthetic gene drive system for local, reversible modification and suppression of insect populations. Curr Biol 23(8):671-677

Akbari OS, Bellen HJ, Bier E et al (2015) Safeguarding gene drive experiments in the laboratory. Science 349(6251):927-929

Australian Academy of Science (2017) Synthetic gene drives in Australia: implications of emerging technologies. https://www.science.org.au/support/analysis/reports/ synthetic-gene-drives-australia-implications-emerging-technologies

Aven T, Baraldi P, Flage R, Zio E (2014) Uncertainty in risk assessment: the representation and treatment of uncertainties by probabilistic and non-probabilistic methods. Wiley, Chichester, UK

Baltzegar J, Barnes JC, Elsensohn JE et al (2018) Anticipating complexity in the deployment of gene drive insects in agriculture. J Resp Innov 5(sup1):S81-S97

Bartumeus F, Costa GB, Eritja R et al (2019) Sustainable innovation in vector control requires strong partnerships with communities. PLOS Negl Trop Dis 13(4):1-5

Basgall EM, Goetting SC, Goeckel ME et al (2018) Gene drive inhibition by the anti-CRISPR proteins AcrIIA2 and AcrIIA4 in Saccharomyces cerevisiae. Microbiology 164(4):464-474

Benjamin EO, Wesseler JH (2016) A socioeconomic analysis of biocontrol in integrated pest management: a review of the effects of uncertainty, irreversibility and flexibility. NJAS Wageningen J Life Sci 77:53-60

Bhatt S, Weiss DJ, Cameron E et al (2015) The effect of malaria control on Plasmodium falciparum in Africa between 2000 and 2015. Nature 526(7572):207-211

Brossard D, Belluck P, Gould F, Wirz CD (2019) Promises and perils of gene drives: navigating the communication of complex, post-normal science. Proc Nat Acad Sci 116(16):7692-7697

Brown Z (2017) Economic, regulatory and international implications of gene drives in agriculture. Choices 32(2)

Buchthal J, Evans SW, Lunshof J et al (2019) Mice against ticks: an experimental communityguided effort to prevent tick-borne disease by altering the shared environment. Phil Trans $\mathrm{R}$ Soc B 374:20180105

Burt A (2003) Site-specific selfish genes as tools for the control and genetic engineering of natural populations. Proc Biolog Sci 270(1518):921-928

Burt A (2014) Heritable strategies for controlling insect vectors of disease. Philo Trans R Soc B 369:20130432

Burt A, Trivers R (2006) Genes in conflict. Harvard University Press, Cambridge, MA

Campbell K, Beek J, Eason C et al (2015) The next generation of rodent eradications: innovative technologies and tools to improve species specificity and increase their feasibility on islands. Biolog Conserv 185:47-58

Carroll C, Lacy RC, Fredrickson RJ et al (2019) Biological and sociopolitical sources of uncertainty in population viability analysis for endangered species. Sci Rep 9:10130

Champer J, Liu J, Oh SY et al (2018) Reducing resistance allele formation in CRISPR gene drive. PNAS 115(21):5522-5527

Craig G, Hickey W, VendeHey R (1960) An inherited male-producing factor in Aedes aegypti. Science 132(3443):1887-1889

Curtis C (1968) Possible use of translocations to fix desirable genes in insect pest populations. Nature 218:368-369

Dicarlo JE, Chavez A, Dietz SL et al (2015) Safeguarding CRISPR-Cas9 gene drives in yeast. Nat Biotechnol 33:1250-1255

EFSA (n.d.). Environmental risk assessment. https://www.efsa.europa.eu/en/topics/topic/ environmental-risk-assessment 
Emerson C, James S, Littler K, Randazzo F (2017) Principles for gene drive research. Science 358(6367):1135-1136

Esvelt KM (2017) Precaution: open gene drive research. 355(6325):589-590

Esvelt K, Smidler A, Catteruccia F, Church G (2014) Concerning RNA-guided gene drives for the alteration of wild populations. eLife 17(3)

Feachem R, Chen I, Akbari O et al (2019) Malaria eradication within a generation: ambitious, achievable, and necessary. Lancet 394(10203):1056-1112

Gantz VM, Bier E (2015) The mutagenic chain reaction: a method for converting heterozygous to homozygous mutations. Science 348(6233):442-444

Gantz VM, Jasinskiene N, Tatarenkova O et al (2015) Highly efficient Cas9-mediated gene drive for population modification of the malaria vector mosquito Anopheles stephensi. PNAS 112(49):E6736-E6743

General Assembly of the United Nations (1997) Convention on the law of the non-navigational uses of international watercourses. United Nations, New York

Glover B, Akinbo O, Savadogo M et al (2018) Strengthening regulatory capacity for gene drives in Africa: leveraging NEPAD's experience in establishing regulatory systems for medicines and GM crops in Africa. BMC Proc 12(Suppl 8):11

Godwin J, Serr M, Barnhill-Dilling SK et al (2019) Rodent gene drives for conservation: opportunities and data needs. Proc R Soc B Biol Sci 286(1914):1606

Grunwald HA, Gantz VM, Poplawski G et al (2019) Super-mendelian inheritance mediated by CRISPR-Cas9 in the female mouse germline. Nature 566:105-109

Hammond A, Galizi R, Kyrou K et al (2016) A CRISPR-Cas9 gene drive system targeting female reproduction in the malaria mosquito vector Anopheles gambiae. Nat Biotechnol 34:78-83

Hammond AM, Kyrou K, Bruttini M et al (2017) The creation and selection of mutations resistant to a gene drive over multiple generations in the malaria mosquito. PLOS Gene 13(10):e1007039

Hartley S, Thizy D, Ledingham K et al (2019) Knowledge engagement in gene drive research for malaria control. PLOS Negl Trop Dis 13(4):e0007233

Hayes KR, Barry S, Beebe N et al (2015) Risk assessment for controlling mosquito vectors with engineered nucleases: sterile male construct. Commonwealth Scientific and Industrial Research Organisation, Hobart

Hayes KR, Hosack GR, Dana GV et al (2018a) Identifying and detecting potentially adverse ecological outcomes associated with the release of gene-drive modified organisms. J Respons Innov 5(supp1):S139-S158

Hayes K, Hosack G, Ickowicz A et al (2018b) Risk assessment for controlling mosquito vectors with engineered nucleases: controlled field release for sterile male construct. Commonwealth Scientific and Industrial Research Organisation, Hobart

James S, Collins FH, Welkhoff PA et al (2018) Pathway to deployment of gene drive mosquitoes as a potential biocontrol tool for elimination of Malaria in Sub-Saharan Africa: recommendations of a scientific working group. Am J Trop Med Hyg 98(6 Suppl):1-49

Kaebnick GE, Gusmano MK, Murray TH (2014) The ethics of synthetic biology: next steps and prior questions. Hast Cent Rep 44:S4-S26

Kaplan S, Garrick BJ (1981) On the quantitative definition of risk. Risk Anal 1(1):11-27

Kessler C (2011) Invasive species removal and ecosystem recovery in the Mariana Islands; challenges and outcomes on Sarigan and Anatahan. In: Veitch CR, Clout MN, Towns DR (eds) Island invasives: eradication and management. Proceedings of the international conference on Island invasives. IUCN and Centre for Biodiversity and Biosecurity, Gland, Switzerland/ Auckland, pp 320-324

King KF, Kolopack P, Merritt MW, Lavery JV (2014) Community engagement and the human infrastructure of global health research. BMC Med Ethic 15(1):84

Kolopack P, Lavery J (2017) Informed consent in field trials of gene-drive mosquitoes. Gates Open Res 1:14)

Kolopack PA, Parsons JA, Lavery JV (2015) What makes community engagement effective?: Lessons from the eliminate dengue program in Queensland, Australia. PLOS Neg Trop Dis 9(4):e0003713 
Kyrou K, Hammond AM, Galizi R et al (2018) A CRISPR-Cas9 gene drive targeting doublesex causes complete population suppression in caged Anopheles gambiae mosquitoes. Nat Biotechnol 36:1062-1066

Lavery JV, Tinadana PO, Scott TW et al (2010) Towards a framework for community engagement in global health research. Trend Parasitol 26(6):279-283

Maiga A (2018) Arrete No 2018-453/MESRSI/SG/ANB. Ouagadougou: Ministere de l'Enseignement Superieur, de la Recherche Scientifique et de l'Innovation

Marshall JM (2009) The effect of gene drive on containment of transgenic mosquitoes. J Theor Biol 258(2):250-265

Moro D, Byrne M, Kennedy M et al (2018) Identifying knowledge gaps for gene drive research to control invasive animal species: the next CRISPR step. Glob Ecol Conserv 13:e00363

National Academies of Sciences, Engineering, and Medicine (2016) Gene drives on the Horizon: advancing science, navigating uncertainty, and aligning research with public values. The National Academies Press, Washington, DC

National Academies of Sciences, Engineering, and Medicine (2017) Preparing for future products of biotechnology. The National Academies Press, Washington, DC

National Research Council (2005) Decision making for the environment: social and behavioral science research priorities. The National Academies Press, Washington, DC

NEPAD and the African Union (2018) Gene drives for Malaria control and elimination in Africa. https://www.nepad.org/publication/gene-drives-malaria-control-and-elimination-africa.

Nicholson E, Possingham HP (2007) Making conservation decisions under uncertainty for the persistence of multiple species. Ecolog Appl 17(1):251-265

Noble C, Min J, Olejarz J et al (2019) Daisy-chain gene drives for the alteration of local populations. PNAS 116(17):8275-8282

North AR, Burt A, Godfray HC (2019) Modelling the potential of genetic control of malaria mosquitoes at national scale. BMC Biol 17:26

Oberhofer G, Ivy T, Hay BA (2019) Cleave and Rescue, a novel selfish genetic element and general strategy for gene drive. PNAS 116(13):6250-6259

Oye KA, Esvelt K, Appleton E et al (2014) Regulating gene drives. Science 345(6197):626-628

Pixley KV, Falck-Zepeda JB, Giller KE et al (2019) Genome editing, gene drives, and synthetic biology: will they contribute to disease-resistant crops, and who will benefit? Annu Rev Phytopathol 57(1):165-188

Quinlan MM, Smith J, Layton R et al (2016) Experiences in engaging the public on biotechnology advances and regulation. Front Bioeng Biotechnol 4:3

Rask M, Worthington R (2015) Governing biodiversity through democratic deliberation. Routledge, Oxon/New York

Rausand M (2011) Risk assessment: theory, methods, and applications. Wiley, Hoboken

Redford K, Brooks T, Macfarlane N (2019) In: Adams J (ed) Genetic frontiers for conservation: an assessment of synthetic biology and biodiversity conservation. IUCN, Gland

Ribeiro J, Kidwell M (1994) Transposable elements as population drive mechanisms: specification of critical parameter values. J Med Entomol 31(1):10-16

Roberts A, de Andrade PP, Okumu F et al (2017) Results from the workshop "Problem Formulation for the Use of Gene Drive in Mosquitoes". Am J Trop Med Hyg 96(3):530-533

Roggenkamp E, Giersch RM, Schrock MN et al (2018) Tuning CRISPR-Cas9 gene drives in saccharomyces cerevisiae. G3 Gene Genom Genet 8(3):999-1018

Sánchez CHM, Wu SL, Bennett JB, Marshall JM (2019) MGDrivE: a modular simulation framework for the spread of gene drives through spatially explicit mosquito populations. Method Ecol Evol 00:1-11

Schwaab E (2014) Addressing uncertainty in fisheries science and management. National Aquarium. https://www.aqua.org/Conserve/fisheries

Scott M, Gould F, Lorenzen M et al (2018) Agricultural production: assessment of the potential use of Cas9-mediated gene drive systems for agricultural pest control. J Respons Innov 5(sup1):S98-S120 
Secretariat of the CBD (2000) Cartagena protocol on biosafety to the convention on biological diversity: text and annexes. Secretariat of the Convention on Biological Diversity, Montreal

Secretariat of the CBD (2011) Nagoya - Kuala Lumpur supplementary protocol on liability and redress to the cartagena protocol on biosafety. Secretariat of the Convention Biological Diversity, Montreal

Serebrovsky A (1940) On the possibility of a new method for the control of insect pests. Zool Zh 19:618

Singh JA (2019) Informed consent and community engagement in open field research: lessons for gene drive science. BMC Med Ethic 20:54

Sudweeks J, Hollingsworth B, Blondel DV et al (2019) Locally fixed alleles: a method to localize gene drive to island populations. Sci Rep 9(1):15821

Teem JL, Ambali A, Glover B et al (2019) Problem formulation for gene drive mosquitoes designed to reduce malaria transmission in Africa: results from four regional consultations 2016-2018. Malaria J 18(1):347

Thizy D, Emerson C, Gibbs J et al (2019) Guidance on stakeholder engagement practices to inform the development of area-wide vector control methods. PLoS 13(4):1-11

UC San Diego Institutional Biosafety Program (2018) Gene drives. https://blink.ucsd.edu/safety/ research-lab/biosafety/gene-drives.html.

UN Environment Programme (2016) Decision adopted by the parties to the cartagena protocol on biosafety, CBD/CP/MOP/DEC/VIII/18. UNEP/CBD, Cancun, Mexico

UN Environment Programme (2018) Decision adopted by the parties to the cartagena protocol on biosafety, CBD/CP/MOP/DEC/9/13. UNEP/CBD, Sharm El-Sheikh, Egypt

UN General Assembly (1966) International covenant on civil and political rights. United Nations, New York

US EPA (2019) Risk assessment. https://www.epa.gov/risk

Vella MR, Gunning CE, Lloyd AL, Gould F (2017) Evaluating strategies for reversing CRISPRCas9 gene drives. Sci Rep 7:11038

Von Borstel R, Buzzati-Traverso A (1962) On the role of lethal mutants in the control of populations. Radioisotopes and radiation in entomology: proceedings of a Symposium, Bombay, 5-9 December 1960. International Atomic Energy Agency, pp 273-278

Windbichler N, Menichelli M, Papathanos P et al (2011) A synthetic homing endonuclease-based gene drive system in the human malaria mosquito. Nature 473(7346):212-215

World Health Organization (2014) Guidance framework for testing of genetically modified mosquitoes. WHO/TDR, Geneva

Yosef I, Edry-Botzer L, Globus R et al (2019) A genetic system for biasing the sex ratio in mice. EMBO Rep 20(8):e48269

Zhao T, Sundararajan SK, Tseng C-L (2004) Highway development decision-making under uncertainty: a real options approach. J Infra Syst 10(1):23-32 